\title{
BOOK REVIEW: DI PAOLO, Ezequiel, DE \\ JAEGHER, Hanne \& CUFFARI, Elena. Linguistic Bodies: \\ The continuity between Life and Language. (MIT Press, 2018, 414 \\ pages)
}

\author{
NARA MIRANDA FIGUEIREDO \\ https://orcid.org/0000-0003-0270-7467 \\ University of Campinas \\ Center for Logic, Epistemology and History of Science \\ Campinas, SP \\ Brazil \\ naramfigueiredo@gmail.com
}

\author{
Article info \\ CDD: \\ Received: 23.03.2020; Accepted: 23.03.2020 \\ http://doi.org/10.1590/0100-6045.2020.V43N1.NF
}

\section{Keywords}

Enactivism

Embodied Cognition

Linguistic Bodies

Language

Abstract: In this review, I briefly explain some of the key concepts of the book in order to offer a panoramic view of the theory of linguistic bodies. Following the book's structure, I first describe the authors' notion of body, then refer to their notion of dialectics, after that, I expose the steps of the model and, finally, get to their conception of languaging.

\section{INTRODUCTION}

Di Paolo, De Jaegher and Cuffari begin the book by inviting the reader to see herself as a linguistic body. They 
list individual and social daily activities that are always permeated by reasons, emotions, choices, thoughts and mental conversations and ask what would be the best way to approach a linguistic body to talk about its nature. The authors' choice is to explain, from the beginning, what linguistic bodies are. Therefore, the book is divided into three parts: In the first, the authors offer their definition of a body, in the second, they discuss what linguistic bodies are, and in the third they focus more specifically on how we become linguistic bodies and how the language we know is part of our actions. These three parts comprise a total of 12 chapters and 414 pages, including glossary, notes, bibliography and index, and are entitled 'Bodies', 'Linguistic Bodies' and 'Living as Linguistic Bodies', respectively.

The authors claim that the theory of linguistic bodies is the first coherent embodied and social conception of human language that doesn't resort to mental representations in order to explain any cognitive processes, including language itself. In order to contextualize the work, we should briefly recall that since the sixties the brain has been conceived as the center of cognitive processing and that theories about cognition, strongly influenced by Fodor's philosophy (1975, 1983), sustained that cognitive processes are operations on mental representations of the world. Only in the eighties, under the influence of Gibson (1979), who argued that perception is 'for action', the representationalist conception began to lose space for less traditional conceptions that argued that cognition also occurs in the body (embodied), in the environment (embedded) and in action (enactive) ${ }^{1}$. The

${ }^{1}$ We should also mention 'extended'. It means that cognitive processes essentially involve our relation to things (our notebooks, for memory, for example) (Chalmers and Clark, 1998). Embodied, embedded, extended and enactive cognition comprise what is 
work of Varela, Thompson and Rosch (1991) is the main reference for embodied cognition and it provides the basis for the theory of linguistic bodies, which I call linguistic enactivism.

Linguistic enactivism, according to the authors, expands and deepens the enactive theory presented by Varela, Thompson and Rosch (1991), connecting dynamic explanations of action and perception to language. Its main aim is to show that the thesis of embodied cognition, contrary to what the critics of this conception suggest, can explain both basic skills, such as the sensorimotor ones, as well as higher skills, such as language. To provide this explanation, Di Paolo, De Jaegher and Cuffari stress that the distance between these two levels of cognitive activities has, until today, been little explored and that we can, at least in principle, imagine that they are of the same nature. Then, according to them, we need to significantly deepen our conception of the body (p.4). This is done in the book by exploring several concepts proposed by enactivism. The authors develop some of these concepts and present others and, after that, they present a conceptual model of cognition that leads us to the notion of linguistic agency, which is a key notion for considering reference, grammar, symbols and other features of language.

This review consists of a brief exposition of the book and offers a panoramic view of the theory. Following the structure of the book, I will first explain the authors' notion of body, then refer to their notion of dialectics, after that I will expose the steps of the model and, finally, get to their conception of languaging.

today called 4E cognition (Newen, Gallagher, \& Bruin, 2018) and might even become 7E cognition (Johnson, 2018) if it comes to include emotional, evolutionary, and exaptative. 


\section{THE THEORY}

The authors start from the analysis of different traditional conceptions of the body: (1) the biological body, which is often considered from a purely functional perspective, and explains the development and functioning of parts essential to language, such as the brain, vocal structures, hearing, gestures, movements, etc.; (2) the situated body, which is anatomically structured and recognized by its patterns of action and linguistic behaviors; (3) the phenomenological body that, differently from functionalist conceptions, is considered from the experience of language in a world of sensations, feelings and emotions, such as desires, suspicions, care, love, confinement, respect, etc; and (4) the social body that is seen as an active body that acts socially, a body that not only uses language for communication, but that linguistically structures its practices, thoughts, rituals, places and institutions. This is a concept of corporeality as powers that spread from social practices among individuals with the development of skills (p.14).

However, the adoption of contextualized conceptions in which the body is considered only from one perspective is rejected by the authors because it is a type of "feeble pluralism lacking a theoretical core" (p.14). Thus, they seek a theoretical articulation that is capable of offering an understanding of the interconnections between the various dimensions of the body leading to the concept of linguistic bodies. This theoretical articulation has several key concepts $^{2}$, among them, the concepts of precariousness,

2 Many of them are concepts borrowed or developed from enactivism, ultimately referring to the book 'The Embodied Mind' of Thompson, Varela and Rosch (1991). Some of them amount to other authors, like Hegel (1976), Jonas (1966, 1968), Simondon 
auto-poiesis, interest (concern), identity, adaptivity, autonomy, appreciation, adaptivity, agency, mastery, sensemaking, social interaction, and, in my understanding, the concept of dialectics connecting them all.

Dialectics, roughly speaking, is not understood in the usual way, namely, as the confrontation of opposite sides of a debate, but as constant tensions that originate between multiple relations that constitute a system. These tensions are due to the disharmony and contradictions of operating trends between different parts, norms or functions (p.114) of the system. "When a passage out of a dialectical situation into another occurs, oppositions are transformed rather than equilibrated" (p.114).

The thesis presented in the book is that dialectical tensions occur between the most diverse opposing trends. At the corporeal level, they occur between and within the body's own dimensions, which are: organic, sensorimotor and intersubjective. The organic dimension of the body is characterized by "anatomical structures or physiology, or as bundles of sensors, effectors, and neuromuscular tissues" (p.24), physicochemical processes of the organism, metabolic, immunological processes etc., and precarious processes of self-individuation and adaptive engagement (coupling) with the environment. These structures and processes can be, and in general are, explained by investigations in the natural sciences. The normativity of the organic dimension is the result of the interactions between these elements and processes. The sensorimotor dimension involves the processes of engagement (coupling) of the agent with the environment. These processes are not separated from neurobiological processes or from the relationships of organisms with other agents (p.21). Its normativity occurs

(1957, 2005), Riegel (1976, 1979), Harris (1981, 1996, 2004), and others. I won't explain these concepts here.

Manuscrito - Rev. Int. Fil. Campinas, v. 43, n. 1, pp. 151-170, Jan-Mar. 2020. 
due to these interactions. The intersubjective dimension is characterized by the agent's interaction with other agents that relate to him/her not only as objects of contemplation, obstacle or use, but as powers of interpellation, which inquire him/her, ignore him/her, support him/her, respond to him/her, smile, cry, and share a world of activities and concerns with him/her (p.62).

Within the organism, dialectical tensions occur even between the tendencies of self-production and selfdistinction. Every living organism is an autopoietic system. Autopoietic systems are autonomous, in the sense that they self-regulate, but they are not independent, as they need means for self-production. Autopoietic systems can be defined as networks of "biochemical processes organized in such a way that the operation of these processes" (p.329) support the organism and its relations with the environment. These processes involve the system's self-distinction in relation to the environment, as well as the system's selfproduction from the environment. Self-production is the process by which the system uses matter and energy, from the environment for its own self-organization; and selfdistinction is the process of rejecting the matter and energy from the environment. Self-production and self-distinction interact dialectically by means of agency. This means that the organism adaptively regulates its coupling with the world selecting what it accepts and what it rejects from the world.

Dialectical tensions - and the overcoming of the tensions by means of transformations and mutual influences constitute the normativity of a certain domain, which interacts with the normativity of other domains, ultimately resulting in the behavior that we observe in interactive encounters. This is why, in my view, the notion of dialectics is so important: because it identifies the very source of normativity. 
Thus, we have individual normativity followed by interactive normativity, which is the idea that in social encounters, two or more organic systems self-regulate, for the interplay of their own sensorimotor normativities and the natural caring constitutes a dialectic tension, and the very interaction is dialectic. At this point, the concepts defining the organism and its interaction with the world and with others already give room to what is called sense-making, which is defined as "The active adaptive engagement of an autonomous system with its environment in terms of the differential virtual implications for its ongoing form of life. The basic, most general form of all cognitive and affective activity manifested experientially as a structure of caring." (p.332). As sense-making can be done jointly and it is affected by coordination patterns, breakdowns and recoveries undergone during social encounters, participatory sense-making comes into play. Participatory sense-making is "the coordination of intentional activity in interaction, whereby individual sense-making processes are affected and new domains of social sense-making can be generated that were not available to each individual on her own" (p.73)

\section{THE MODEL}

The dialectical model of cognition ${ }^{3}$ presented by the authors starts from participatory sense-making and builds up through seven other dialectic steps leading us to the notion of linguistic agency. But it is not until chapters seven and eight that the reader can have an overview of these steps.

3 The theory of linguistic bodies as a whole aims to show "the logic of the activity of using language" (p.133). The dialectical model of how participatory sense-making leads to linguistic agency is part of the theory. 
Each step, as the authors mention in the description of the visual representation of the model, is a form of social agency, "it breaks into its main form of tension" (p.160) and generates, or leads to, the next step. From this point on, things start to get very interesting, for the authors resort to theories of language, developmental psychology, phenomenological analysis and empirical research and consider "work in conversation analysis, interaction studies, and ethnography (p. 341)" as source of empirical evidence about social interactions 4 .

I will briefly explain a couple of the key steps of the model and refer to the others. Participatory sense-making breaks into individual norms and interactive norms. As I mentioned before, individual norms are constituted by the essential tensions between self-production and self-distinction among the three dimensions of embodiment ${ }^{5}$. Each interactive situation has its own interactive norms, which are constituted

${ }^{4}$ Several references are provided in the book, I'll name a few: Sacks (1992), Lakoff and Johnson (1980, 1999) Goodwin (1981, 986), Gibbs and Cameron (2008), Bakhtin (1984, 1986), Goffman (1959), Voloshinov (1929), Du Bois 920140, Andrén (2017), Sapir (1927), Popova (2015). This short list is merely to give the reader a general idea of the amount of work on which the theory of linguistic bodies is based.

5 Keep in mind that we are talking about situated (embedded) bodies, which interact constantly with others and with the world. These processes don't start from the individual. They are constantly developing and immersed in networks of relations. The theory is an attempt to abstract and objectify parts of these processes which are constantly happening. As all abstraction and objectification, according to the authors, it has its limitations, and it will always have. It is worth noting that the very concepts of abstraction and objectification have its own specific definitions in the book. I am using them here according to these definitions. 
by the combination of the individual normativities. In practical terms, a good example for this autonomous normativity of interactive situations is the narrow corridor case: linguistic body A wants to walk through a narrow corridor towards the exit of the building while linguistic body $\mathrm{B}$ is coming on the opposite direction, both people want to pass by each other, but they bump into each other a few times before being able to pass by, because the corridor is narrow and the space is restricted. Both agents, together, self regulate their actions, despite the fact that they are not explicitly intentionally coordinating ${ }^{6}$ their actions at first (p.142), otherwise they wouldn't bump into each other.

From the tension entailed by participatory sense making, we get to social acts which split to the tension between spontaneous acts and partial acts. In a nutshell, this is the difference between acts that require feedback and acts that do not. For example, when greeting, linguistic body A expects to be greeted back by linguistic body B, while just stretching does not involve any kind of feedback. From this tension, there is the coordination of social acts, which splits into creative and recursive acts. Shortly, recursive acts reproduce previous acts and reiterate them, while creative ones are new. From this tension, we have the normativity of social acts which splits into local pragmatics and portable acts, which can be synthetized in acts that are meaningful only in specific groups - local - and acts that can be enacted in several groups - portable. Internal jokes are examples of local pragmatics, while greetings are examples of portable acts. This tension leads to communities of interactors. Its tension is between two kinds of roles: regulatory role and regulated role. There is a good

\footnotetext{
6 I would like to refer here to the important concepts of dissonance and synergy. Although I shall not go into the details here, these concepts are fundamental for explaining social interactions.
} 
example for this case: in face-to-face conversation, usually, people keep a certain distance from each other; this is coregulated by the individuals in the situation they are living. If, for example, there is something preventing the understanding between them, linguistic body A can get closer to linguistic body B in an attempt to hear better - this is a regulatory act. It says that the conversation must be clearer or louder, it is almost like a requirement for the conversation to keep going. A regulatory act is, then, “(...) a partial act used in order to modulate, select, project, reject, or encourage other particular partial acts within a shared repertoire." (p. 331). The regulated act, on the other hand, is the partial act that complements the regulatory act. Naturally, linguistic body B can enact another regulatory act to which linguistic body A will either conform or confront ${ }^{7}$.

The tension between regulatory and regulated roles leads to dialogue and recognition, the sixth step of the model. It splits into production of utterances and interpretation of utterances. Before referring to the tension, it is important to highlight that utterances are not understood as we traditionally do, namely, as statements that involve sentences in spoken or written language, nor as linguistic gestures. Although these can also be examples of utterances, utterances are essentially acts. An utterance is "A dialogic act, enacted asymmetrically through the actions of a mutually recognized producer and an audience." (p. 332). They have a double dimension of meaning (p.175): they contribute to the co-regulation of interactive encounters, which is its pragmatic dimension, and they are meaningful due to how they relate to the participants of the encounters, which is its expressive dimension (p.176). As I just mentioned, the tension that happens in dialogue

7 'Conform' and 'confront' are not specific concepts used by the authors, just my words to explain the relation between the two roles. 
and recognition is between interpretation and production. Interpretation is the act of the listener (audience or apprentice) before the producer. Production is the act of a producer, which is someone who performs the utterance, before the audience. Thus, "The utterance as a whole is a social act in the sense we have given to this term: it is constructed as much by the audience as by the producer and may fail if the corresponding complementary acts are not coordinated" (p. 174).

From production and interpretation of utterances in a dialogue, we come to participation genres. "Participation genres encompass the practices and situated norms of different kinds of social interaction, a subset of which are Bakhtin's speech genres." (p. 179). Participation genres frame the production of utterances and what is required for interpretation, and they help to coordinate the regulation of social acts. They split into self-control and mutual interpretation. Mutual interpretation is the act of interpreting himself/herself and others. Self-control is the act of the producer when he/she interprets his/her own utterances due to dialogical regulation. "In other words, mutual interpretation leads to self-interpretation and to the selfregulation of utterance production" (p. 184) which leads to social self-control.

The final step of the model is reported utterances, which splits into incorporation and incarnation and it has a transformative potential that leads to a "new kind of embodied agency: linguistic bodies" (p.191). Reported utterances are "utterances that echo, reflect, refract, or somehow make use of other utterances, the producer's own or those of others." (p.187). It brings up "the producer's interpretation of the utterances it repeats or reflects (Voloshinov 1929/1973, 117)." (p.187). Incorporation is when external processes become constitutive of a system; it is the appropriation of utterances of other agents by a 
linguistic agent. Incorporated utterances are a result of personal enactments and patterns of a community. These acts "may sometimes lie deep in the past of a community's linguistic experience" (p.191) and they define a linguistic agent. Incorporation "entails the incarnation of other linguistic agents, their perspectives, attitudes, voices, gestures, movements, personalities, ways of relation and so on"8 (p.194). This is the paradox of linguistic bodies: "acts of utterance incorporation define a linguistic agent, but the process of incorporation simultaneously entails the incarnation of other linguistic agents" (p.194). This is explained by means of virtual dialogues. Self-directed utterances, "a social skill put to personal use" (p.125), entail a dialogic attitude, even when there is no actual interlocutor (or audience). Thus, virtual dialogues "can be enacted by a single linguistic agent if in addition to invoking the presence of (specific or indeterminate) others, these others are also incarnated - that is, 'animated' as agents and given a part in the construction of the virtual dialogue." (p.194). The ongoing management of this last tension of the model, namely, incorporation and incarnation, defines a linguistic body.

Objectivity is another concept worth mentioning before we come to how the authors propose that grammar develops from the continuity between life and mind. The claim is that it has been part of the model all along as it emerges through collaborative processes of sense-making. Objectivity is conceived as "the activity of taking something as a thing, a this that is the object of our treating, doing, acting, or uttering" "(p.200). The objectification happens when, by repeating an utterance we bring "that utterance to presence

\footnotetext{
${ }^{8}$ My italics

${ }^{9}$ My italics.
} 
(i.e., to shared attention and awareness); in so doing, we have made it a possible object of shared regulatory action; and we have also opened up the possibility of appreciating the utterance, of letting it be, of lingering there with us." (p. 203). The objectifying attitude is, then, "the practice of regulating other practices and experiences in a mutually constraining relation with sociomaterial conditions" (p. 203).

\section{LANGUAGING}

Let us now move to the emergence of language. First, in chapter nine, the authors consider how we become linguistic bodies. They suggest that "children even at or before birth, experience full linguistic engagement" (p. 258) and that we are always unfinished beings, "constantly in becoming" ( $p$. 218). After that, in chapter ten, they consider how research about autism can help not only to improve the model but also in our understanding of autism and non-autistic linguistic bodies. In chapter eleven, they start exploring how language as we know it (when we study grammar, narratives, symbols and so on) emerges from our living practices. They say that "It is not the case that in considering grammar, symbol, convention, and written language (...), we have finally built our way up to the inevitable plane where ideal entities of higher-order cognitive abilities hang out" (p.279). But in seeing the sensitivities and powers of linguistic agency throughout the book, we can consider words, syntax and symbols differently (p.279). In reference to Ochs (1996) and Sapir (1927), they say that grammar is immersed in social interaction and language interpenetrates with experience. Thus, the enactive take is probably "compatible with research that links grammar to a logic of practices, material structures and social relations" (p. 280). Besides that, linguistic enactivism adds that several phenomena, such as 
"Sensitivities to symbols, grammar, convention, regulation, narrative" (p.280) can be explored from a linguistic enactivist perspective which considers, "the joint structuring and mutual accommodation of repertoires, the normative regulation of interactive encounters (...)" (p.280), bodily, interactive and societal autonomy, and the tensions of incorporation and incarnation.

According to linguistic enactivism, grammar "can be understood as a dynamic and local organizing activity of linguistic bodies" (p. 281). Regulating patterns can be identified since the first tension described in the model, the tension between individual norms and interactive norms. The authors point out that "(...) unspoken regulative patterns (...) help coordinate the construction of utterances. Emergent grammatical patterns (...) are in essence no different from (...) more obviously embodied and interactive forms of coregulation" (p.287). Grammatical rules are the objectification of these patterns. The preferred word for talking about grammar is 'grammaticalizing', as much as 'languaging' "referring, regulating, judging, symbolizing, and sensitizing" (p. 293) which preserve "the materiality, agency, and susceptibility of these processes" (p. 293), while 'reference', 'rules', 'content', 'symbol' and alike keep the idea of language as a set of abstract rules, somehow independent of living bodies.

"Referring, then, is an emerging outcome of sensemaking processes of linguistic bodies becoming together" ( $p$. 295). And because "linguistic bodies also symbolize and interact with symbols as "products"' (p. 295) of the processes of becoming linguistic bodies, a "novel materiality, asymmetry, and temporality" (p. 307) emerges. One that allows us to enact ourselves "through engagements with the utterances of another" (p. 307) when writing and reading, for example, and to understand voices "uttered by no body" (p. 
308), in advertisements, political messages, institutional rules, guiding symbols, norms in our communities and so on.

The book ends considering some ethical issues implied by the theory. Once we accept that we are intersubjective bodies, constantly interacting not only with other linguistic bodies but also with utterances that do not have a specific enunciator, such as the ones just mentioned, we immediately see that the essential character of living beings of caring about life "because we are precarious organic, sensorimotor, and intersubjective bodies" (p. 309), our embeddedness in a world of others, and our constant becoming by means or incorporation and incarnation leads us directly to the embeddedness of ethical concerns. Linguistic agency is a form of ethical agency because it "is only with the appearance of the critical and person-constituting powers of linguistic bodies that questions of what kinds of worlds we are building, for whom, and under what constraints and possibilities, first become issues in the history of life" (p. 10), and due to this, as put by Varela (1999a) "the turn toward concrete situated practices in the study of the mind should be accompanied by a similar turn toward concrete ethical know-how" (p. 350).

\section{CONCLUDING REMARKS}

In short, we are linguistic bodies because we are, even before birth, immersed in a world of others and of several needs and constraints for life maintenance. These conditions mean that things are inherently meaningful to us. What we traditionally understand as language, is a development of several layers of complexity in our forms of life.

The main points to be highlighted in this theory, in my view, are (1) the source of normativity in the dialectical 
tensions and its natural character; (2) the idea that life itself is a dialectic tension between self-production and selfdistinction that involves selective opening and selective rejection (adaptive regulation) (p.40); (3) the explanation of how language, as we know it, emerges from this natural normativity, which encompasses the whole dialectical model; (4) the perspective that we are essentially social beings, and (5) that because things are essentially meaningful to us, including being bad or good, the theory also involves ethical issues and gives room for the development of ethical agency from an enactive perspective.

As mentioned more than once throughout the book, this is not a finished work. Several points need to be developed, complemented and corrected. Besides that, "the model is not meant to describe the unfolding of historical stages in the evolution of human language or the development of linguistic skills" (p.133). The theory aims at extending "the remit of enactive theory" (p.133) in exposing the logic of the activity of using language (p.133). Also, the authors "do not end the book (...) with broad enactive accounts of symbols or grammar" (p. 10), but, despite its unfinished character, one can see that this book is the result of many years of research and dedication. Some concepts can be explored in more detail if one looks for specific papers; I should mention the very concept of participatory sensemaking (De Jaegher \& Di Paolo, 2007), the concept of agency (Barandiaran, Di Paolo, \& Rohde, 2009) and sensemaking and language (Cuffari, Di Paolo \& De Jaegher, 2015) ${ }^{10}$, but there are several references throughout the book.

10 One can also search online for talks given by the very authors which offer good overviews of their theory. I should specifically mention a couple of videos made exclusively to present their work 
It is a very dense book, the theory is intricate and sophisticated, but it is totally worth the reading. For those working on embodied cognition, either by endorsing it or by questioning it, this is a keystone work and it promises to shake up our conceptions. For those not specifically working on that, it might be a little challenging, but it certainly provides an entirely different conception of mind and life. This book offers an insightful and fascinating perspective on the long-standing problems of the relationship between body and mind.

\section{REFERENCES}

ANDRÉN, M. (2017). Children's expressive handling of objects in a shared world. In C. Meyer, J. Streeck, \& J. S. Jordan (Eds.), Intercorporeality: Emerging Socialities in Interaction (pp. 105-141). Oxford: Oxford University Press.

Bakhtin, M. M. (1984). Problems of Dostoevsky's Poetics (C. Emerson, Trans.). Minneapolis: University of Minnesota Press.

BAKHTin, M. M. (1986). Speech Genres and Other Late Essays (V. W. McGee, Trans.). Austin: University of Texas Press.

Barandiaran, X. E., Di Paolo, E. A., \& Rohde, M. (2009). Defining agency: Individuality, normativity,

in a symposium dedicated to the book, which was held during the 2nd Meeting on Cognition and Language, in 2019, and is available on youtube on the channel "Cognição \& Linguagem":

https://www.youtube.com/playlist?list=PLTpRvDsWfOhDMa5 NpdqSPXE_-OWu_1efV 
asymmetry, and spatio-temporality in action. Adaptive Behavior, 17(5), 367-386

Chalmers D., Clark, A. (1998) "The extended mind". Analysis. 58 (1): 7-19. doi:10.1093/analys/58.1.7

Cuffari, E., Di Paolo, E. A., \& De Jaegher, H. (2015). From participatory sense-making to language: There and back again. Phenomenology and the Cognitive Sciences, 14(4), 1089-1125.

De Jaegher, H., \& Di Paolo, E. A. (2007). Participatory sense-making: An enactive approach to social cognition. Phenomenology and the Cognitive Sciences, 6, 485-507.

Du BoIs, J. W. (2014). Towards a dialogic syntax. Cognitive Linguistics, 25(3), 359-410.

JoHnson, M. (2018) The Embodiment of Language in The Oxford Handbook of 4E Cognition. "Newen, S. Gallagher, \& L. de Bruin (Eds.) Oxford: Oxford University Press.

FODOR, J. A., 1975 The Language of Thought, Cambridge, MA: Harvard University Press.

FODOR, J. A., 1983. The Modularity of Mind, Cambridge, MA: MIT Press.

Gibson, J. J., 1979 The Ecological Approach to Visual Perception, Taylor \& Francis Group.

Goffman, E. (1959). The Presentation of Self in Everyday Life. New York: Anchor Books.

GOODWIN, C. (1981). Conversational Organization: Interaction between Speakers and Hearers. New York: Academic Press. 
GoodwIn, C. (1986). Audience diversity, participation and interpretation. Text, 6(3), 283-316.

Hegel, G. W. F. (1807/1976). Phenomenology of Spirit (A. V. Miller, Trans.). Oxford: Oxford University Press.

JONAS, H. (1966). The Phenomenon of Life: Toward a Philosophical Biology. New York: Harper \& Row.

JONAS, H. (1968). Biological foundations of individuality. International Philosophical Quarterly, 8(2), 231-251.

LAKoff, G., \& Johnson, M. (1980). Metaphors We Live By. Chicago: University of Chicago Press.

LAKOFF, G., \& JOHnSON, M. (1999). Philosophy in the Flesh: The Embodied Mind and Its Challenge to Western Thought. New York: Basic Books.

Newen, S. Gallagher, \& L. DE BRuin (2018) The Oxford Handbook of 4E Cognition. Oxford: Oxford University Press.

Ochs, E., SChegloff, E., \& ThOMPSOn, S. (Eds.). (1996). Interaction and Grammar. Cambridge: Cambridge University Press.

Popova, Y. B. (2015). Stories, Meaning, and Experience: Narrativity and Enaction. London: Routledge.

RIEGEL, K. F. (1976). The dialectics of human development. American Psychologist, 31(10), 689-700.

RIEGEL, K. F. (1979). Foundations of Dialectical Psychology.

SACKS, H. (1992). Lectures on Conversation (2 vols.). Oxford: Blackwell.

SAPIR, E. (1927/1949). The unconscious patterning of behavior in society. In D. G. Mandelbaum (Ed.), 
Selected Writings of Edward Sapir in Language, Culture, and Personality (pp. 544-559). Berkeley: University of California Press.

SimOndON, G. (1958/2017). On the Mode of Existence of Technical Objects (C. Malaspina \& J. Rogove, Trans.). Minneapolis, MN: Univocal.

SimONDON, G. (2005). L'Individuation à la Lumière des Notions de Forme et d'Information. Grenoble: Millon.

Varela, F. J., Thompson, E., \& Rosch, E. (1991). The Embodied Mind: Cognitive Science and Human Experience. Cambridge, MA: MIT Press.

Voloshinov, V. N. (1929/1973). Marxism and the Philosophy of Language (L. Matejka \& I. R. Titunik, Trans.). Cambridge, MA: Harvard University Press.

$((c))$ EY 